
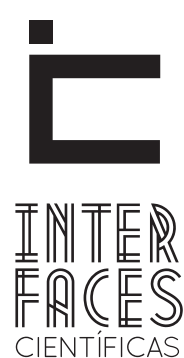

EDUCAÇÃO

ISSN IMPRESSO 2316-333X

ISSN ELETRÔNICO 2316-3828

DOI 10.17564/2316-3828.2015v3n3p109-122

\title{
USO DAS TIC'S NA FORMAÇÃO INTERDISCIPLINAR DOS MUSEÓLOGOS
}

Janaina Cardoso de Mello ${ }^{1}$
Jean Costa Souza

\section{RESUMO}

Este artigo tem como objetivo apresentar um estudo de caso na elaboração de uma tecnologia educacional universitária. 0 site "Teoria e Metodologias da História da UFS" insere-se na perspectiva da elaboração de suportes tecnológicos direcionados às Ciências Humanas e Sociais Aplicadas para o fomento da aprendizagem do futuro profissional em Museologia. A metodologia utilizou a tecnologia disponível no googlesites para a alocação de textos, filmes e vídeos de apoio, sugestões para a disciplina, lista bibliográfica complementar, atividades extra-sala, papers dos textos debatidos em aula, organização de seminários e eventos da disciplina de Teoria e Metodologias da História. A vinculação do site à disciplina ministrada tornou o aprendizado mais prazeroso, desafiador e abrangente, resultando num índice de acessos por mais $80 \%$ dos alunos, com a aprovação de mais de $80 \%$ nas avaliações daqueles que fazem uso do site. 0 desenvolvimento de recursos tecnológicos na área educacional e na área de museus (museus digitais, cibermuseus, sites de museus, dentre outros) aliado ao manuseio da internet como instrumento de mediação das fronteiras do saber traz mais amplitude e eficácia à aprendizagem.

\section{PALAVRAS-CHAVE}

Tecnologia Educacional. Interdisciplinaridade. Museologia. 


\section{ABSTRACT}

This article aims to present a case study on the development of a university educational technology. The site "Theory and methodology of history of UFS" inserts itself in the perspective of development of technological media targeted at Humanities and social sciences Applied to the promotion of learning professional future in museology. The methodology used the technology available on googlesites for the allocation of texts, fil$\mathrm{ms}$ and videos of support, suggestions for discipline, complementary bibliographical list, extra-sala activities, papers of the texts discussed in class, organization of seminars and events of the discipline of Theory and methodology of history. The binding site for the course being conducted become more pleasurable learning, challenging and comprehensive, resulting in an index hits a more $80 \%$ of students, with the approval of more than $80 \%$ in the ratings of those who make use of the site. The development of technological resources in the educational area and in the area of museums (museums digital, cibermuseus, sites of museums, among others) together with the handling of the internet as an instrument of mediation knowledge borders brings more breadth and effectiveness of learning.

\section{KEYWORDS:}

Educational Technology. Interdisciplinarity. Museology.

\section{RESUMEN}

Este artículo tiene como objetivo presentar un estudio de caso sobre el desarrollo de una tecnología educativa de la Universidad. El sitio "Teoría y metodología de la historia de UFS" se inserta en la perspectiva de desarrollo de medios tecnológicos orientados en Humanidades y ciencias sociales aplicadas a la promoción del aprendizaje futuro profesional en museología. La metodología utiliza la tecnología disponible en googlesites para la asignación de textos, películas y videos de apoyo, sugerencias para la lista bibliográfica complementaria, actividades extra-sala, disciplina, papeles de los textos discutidos en clase, organización de seminarios y eventos de la disciplina de teoría y metodología de la historia. El sitio de Unión para el curso que están llevando a cabo con- vertido en aprendizaje más placentero, desafiante y completa, resultando en un hits índice un $80 \%$ más de estudiantes, con la aprobación de más del $80 \%$ en las calificaciones de aquellos que hacen uso del sitio. El desarrollo de los recursos tecnológicos en el área educativa y en la zona de los museos (museos digitales, cibermuseus, sitios de museos, entre otros) junto con el manejo de la internet como un instrumento de las fronteras de conocimiento mediación trae más amplitud y la eficacia del aprendizaje.

\section{PALABRAS CLAVE}

Tecnología Educativa. Interdisciplinariedad. Museología. 


\section{INTRODUCÇÃO}

Nascida no período da Guerra Fria com o nome de ArphaNet a internet desenvolveu-se no campo das estratégias de comunicação militar dos Estados Unidos. De acordo com Abreu (2013, p. 2):

0 apoio financeiro do governo norte-americano através da pesquisa promovida pelo Departamento de Defesa dos Estados Unidos por meio da ARPA - Administração dos Projetos de Pesquisa Avançada, já em 1968, foi o impulso para a implantação do sistema de informação em rede.

Findo o período belicoso, houve uma ampliação do acesso à rede de computadores interligados por cientistas e universidades. 0 surgimento da World Wide Web tornou o ambiente de navegação cibernética mais atraente, incorporando imagens, sons, localização de arquivos e banco de dados (MAYNARD, 2011).

Esse ambiente de navegação é chamado por Lévy (1999, p. 17) de ciberespaço, ou seja, um "novo meio de comunicação que surge da interconexão mundial dos computadores". A terminologia abrange além "da infra-estrutura material da comunicação digital, o universo oceânico de informações que ela abriga, assim como os seres humanos que navegam e alimentam esse universo". Compondo ainda esse panorama conceitual está o neologismo “cibercultura”, definido, também, por Lévy (1999, p.17) como "o conjunto de técnicas (materiais e intelectuais), de práticas, de atitudes, de modos de pensamento e de valores que se desenvolvem juntamente com o crescimento do ciberespaço".

Dado esse contexto de desenvolvimento tecnológico mundial e sua conceituação mais específica, o historiador brasileiro Luciano Figueiredo (1997) foi um dos primeiros a salientar "as experiências da informática aplicadas à História”. Mesmo sendo um texto datado, ao final da década de 1990, o autor ressalta a importância dos editores de texto eletrônicos, programas destinados à confecção de planilhas e bases de dados para os pesquisadores da área da História.
As primeiras bases manipuladas por historiadores pertenciam a demografia e a história econômica, que primeiro sentiram necessidade de armazenar volumes muito grandes de informações recolhidos em fontes históricas e passíveis de serem padronizadas. Registros paroquiais com indicação de nascimento, morte, filiação, condição, idade, sexo da população, números dos mapas contábeis da época, eram recortados e ordenados em verdadeiros armazéns informáticos, que podem ser submetidos a múltiplos cruzamentos conforme a investigação. (FIGUEIREDO, 1997, p. 10).

Luciano Figueiredo (1997) cita ainda a aplicação da informática pelo historiador Guilherme Pereira das Neves em seu estudo prosoprográfico em sua tese de doutorado sobre a Mesa de Consciência e Ordens, bem como a iniciativa de Arquivos Históricos do México (Puebla) e da Espanha (Sevilla) na automatização de instrumentos de consulta documental.

\section{Imagem 1 - Arquivo Geral das Indias (Sevilla - Espanha)}

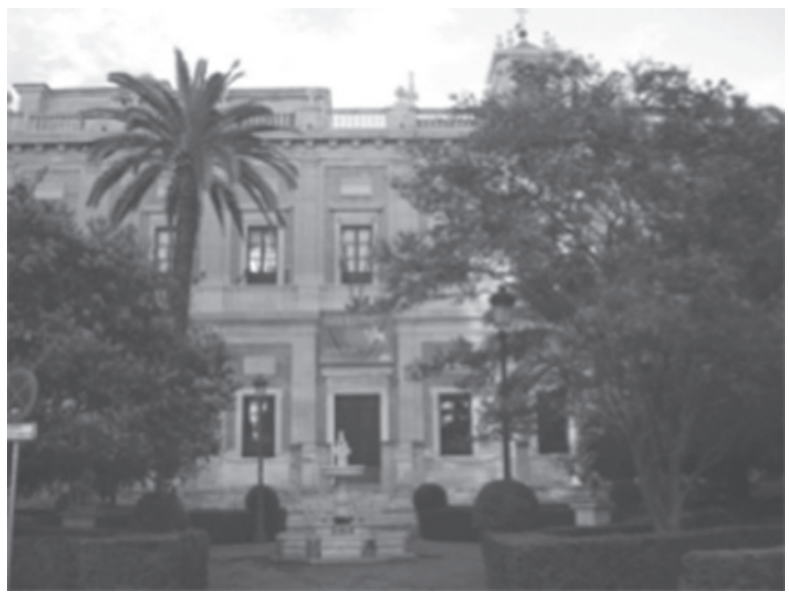

Fonte: Foto Arquivo Pessoal da Pesquisadora (2008).

Mas haveria alguma consonância entre a modernidade tecnológica e a tradição museológica? Á primeira vista a Museologia, enquanto campo de saber autônomo e regulamentado pela Lei $n^{0} 7.287$, de 18 de dezembro de $1984^{3}$, parece estabelecer uma

3. Determina que "o exercício da profissão de Museólogo é privativo: I - dos diplomados em Bacharelado ou Licenciatura Plena em Museologia, por cur- 
vinculação com áreas mais afins a sua tipologia de acervos, como a História, a Antropologia, a Arqueologia e as Artes. Todavia, com o desenvolvimento dos recursos tecnológicos, tanto na área educacional quanto na área museológica (com museus digitais, cibermuseus, sites de museus, dentre outros), o manuseio da internet como instrumento de mediação com conhecimentos fronteiriços termina por adquirir mais amplitude e eficácia.

Assim, o site "Teoria e Metodologias da História da UFS" ${ }^{\prime}$ insere-se na perspectiva da elaboração de suportes tecnológicos direcionados às Ciências Humanas e Sociais Aplicadas para o fomento da aprendizagem do futuro profissional em Museologia.

Trata-se de um processo de usabilidade das ferramentas tecnológicas que permite o desenvolvimento de uma website para melhorar a qualidade da interface e da interação entre homem e computador, técnica e usuário, ou seja, a humanização da técnica. Heemann (1997, p. 25) aponta aspectos essa nova relação entre a técnica e o usuário:

O número de usuários não especialistas cresceu, bem como a demanda pelos sistemas computadorizados que apresentem as características de facilidade de uso e facilidade de aprendizado. Como consequência, essas características dos sistemas computadorizados têm se tornado, cada vez mais, um tópico de importância capital, reconhecido pelos pesquisadores em interfaces homem-computador e a comunidade de usuários.

Nesse sentido, como objetivo geral, esse produto busca constituir-se como um instrumento de informação, pesquisa e interação, tratando de temas con-

sos ou escolas reconhecidos pelo Ministério da Educação e Cultura; II - dos diplomados em Mestrado e Doutorado em Museologia, por cursos ou escolas devidamente reconhecidos pelo Ministério da Educação e Cultura; III - dos diplomados em Museologia por escolas estrangeiras reconhecidas pelas leis do país de origem, cujos títulos tenham sido revalidados no Brasil, na forma da legislação; IV - dos diplomados em outros cursos de nível superior que, na data desta Lei, contem pelo menos 5 (cinco) anos de exercício de atividades técnicas de Museologia, devidamente comprovados". Disponível em: <http:// www.planalto.gov.br/ccivil_03/Leis/L7287.htm>. Acesso em: 08 ago. 2014.

4. Universidade Federal de Sergipe ceituais e metodológicos da área da História que têm sido uma fonte para os diálogos interdisciplinares exercitados pelos profissionais de museus, pois como observa Meneses (1994, p. 12): "não existe museu sem ser histórico".

E se os profissionais de museus precisam aprender a trabalhar em um ambiente interdisciplinar por excelência, os alunos em formação nas áreas das Ciências Humanas e Sociais carecem de um maior entendimento teórico e prático sobre esse conceito tão difundido, mas pouco entendido. Sob esse aspecto parte-se da própria etimologia da palavra para sua compreensão, tomando-o como:

0 prefixo 'inter' dentre as diversas conotações que podemos thes atribuir, tem o significado de 'troca', 'reciprocidade', e 'disciplina', de 'ensino', 'instrução', çiência', Logo, a interdisciplinaridade pode ser compreendida como sendo a troca, de reciprocidade entre as disciplinas ou ciências, ou melhor, áreas do conhecimento. (FEREIRA APUD FAZENDA, 1993, p. 21-22).

Por isso, como objetivos específicos propõe-se aos alunos e professores a apropriação das ferramentas tecnológicas na difusão do conhecimento produzido em sala de aula, bem como nas reflexões extra-sala; permitindo assim no campo da pesquisa um âmbito de rápida exploração de um grande número de hipóteses, o desenvolvimento de um canal de aperfeiçoamento das técnicas de ensino; a ruptura com a concepção tradicional de distanciamento das Ciências Humanas e Sociais Aplicadas da informatização; o estabelecimento de uma linguagem que alie inovação tecnológica e humanização da técnica, com potencial de crítica interpretativa. 
Imagem 2 - Site teoria e metodologia da história (Apresentação)

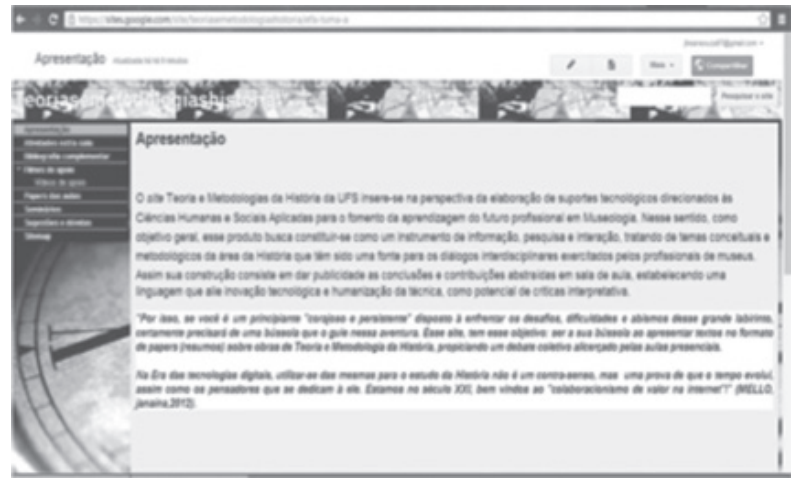

Fonte: https://sites.google.com/site/teoriasemetodologiashistoria

O trabalho, assim, constitui-se na aplicação das ferramentas tecnológicas no âmbito da formação cotidiana de museólogos, inspirando-se no exercício cotidiano de alunos de história que mantém blogs e sites sobre teoria e metodologia, porém sem que estes sejam incorporados de fato ao ambiente acadêmico. No caso do site desenvolvido na graduação em Museologia UFS, existiu também um cuidado no processo comunicativo, uma vez que não se pretende formar bacharéis em História, mas sim fornecer aos futuros museólogos as noções necessárias para que estes quando atuarem em um museu (quer como estagiários, quer como funcionários), possam dialogar de modo inteligível com historiadores e demais profissionais que se baseiem nos conhecimentos históricos como base para as pesquisas, documentação e museografia ${ }^{5}$ institucional.

\section{MÉTODO}

A primeira etapa compreendeu a elaboração de um site armazenado em um domínio gratuito (googlesites) para a alocação de textos, filmes e vídeos de apoio, sugestões para a disciplina, lista bibliográfica complementar, atividades extra-sala, papers dos textos debatidos em aula, organização de seminários e eventos da disciplina de Teoria e Metodologias da História.

A edição das páginas foi feita diretamente no navegador de internet, sem a necessidade de mexer em código fonte. Além da ferramenta para construir o site de graça, o Google oferece hospedagem grátis com 100 MB de espaço em disco e 5 GB de transferência de dados. Oferece ainda total integração com outras ferramentas como Google Apps, analytics e webmaster tools.

A segunda etapa consistiu nas leituras e pesquisa para obtenção de dados que alimentaram periodicamente essa base de dados. Já a terceira etapa compreendeu a inserção das informações no site. A quarta etapa envolveu o gerenciamento do site (atualizações, acompanhamento e avaliação dos comentários) para a visualização e acompanhamento da aprendizagem da turma. Por fim, a quinta etapa desenvolveu-se simultaneamente à quarta etapa, a partir do contato pessoal com os alunos e o feedback da usabilidade dessa ferramenta tecnológica, para a correção de eventuais problemas como dúvidas a respeito do assunto dado, ideias entre alunos e professor entre outros.

Para acesso ao site os alunos podem utilizar os computadores conectados à internet do Laboratório de Memória e Informação Digital (LabTrix) do curso de graduação em Museologia na UFS do Campus Laranjeiras, além da rede wireless que estão disponíveis em todas as salas da instituição de ensino ou as próprias conexões realizadas por meio de suas residências.

5. Para Francisca Hernandés (1971), os estudos da Museografia abordam: "a instalação das colecções, arquitectura climatologia, do edifício administrativo, e assim por diante é uma atividade essencialmente técnica e prática”. 
Imagem 3 - Site teoria e metodologia da história (Atividades Avaliativas)

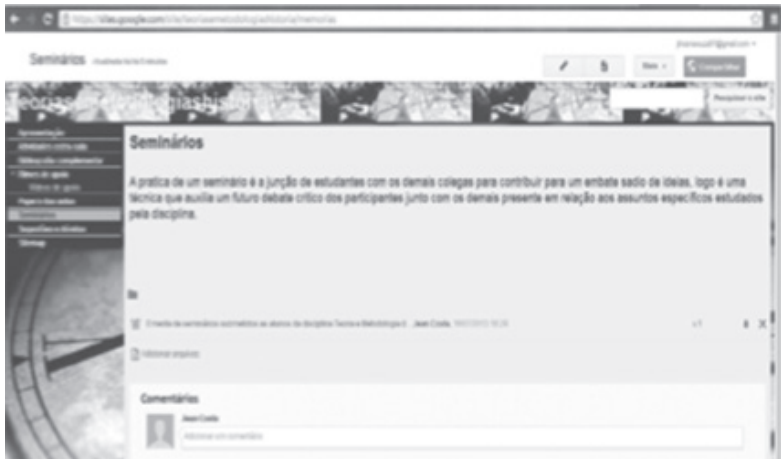

Fonte: https://sites.google.com/site/teoriasemetodologiashistoria

De acordo com Santos (2011, p. 6), uma atividade curricular on-line carece de atenção não apenas ao material de estudos ministrados na aula e inseridos na rede, mas primordialmente na forma como é feita a disponibilização desse material em um ambiente virtual de aprendizagem com seu conjunto de interfaces digitais e múltiplas possibilidades de expressão e interação dos usuários.

Precisou-se atentar para uma seleta de termos ${ }^{6}$ e discussões que contemplassem a Cultura como elemento primordial, uma vez que esse é o aporte fundamental para os estudos dos museus, suas tipologias, acervos e funcionalidades, bem como para a análise do patrimônio cultural material e intangível que orbita o campo de interesse museológico. Relações de poder, economia e política, sociedade e conflitos são incorporadas nas reflexões museológicas a partir de debates interdisciplinares constituídos na História, na Sociologia, na Antropologia, na Filosofia, na Arqueologia e na Literatura, para se pensar a dinamicidade cultural que impulsiona a vida humana em suas rupturas e continuidades.

6. A opção por terminologia e não conceitos isolados permite que palavras e definições sejam vistas de forma integrada em um conjunto de sentidos que expliquem dada realidade.
Imagem 3 - Site teoria e metodologia da história (Papers das aulas)

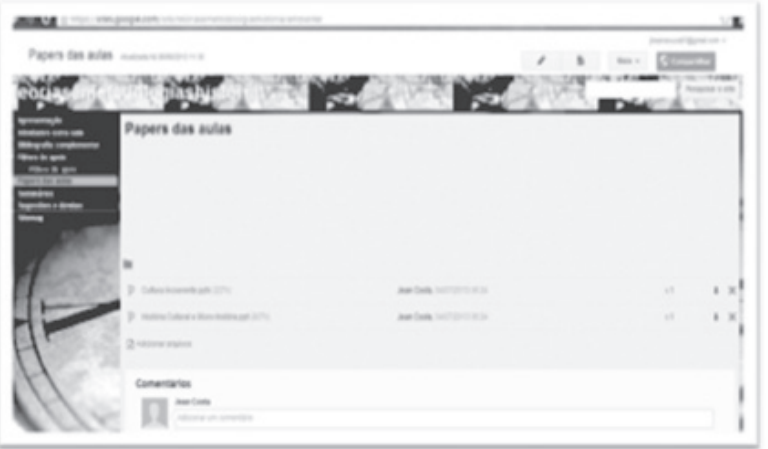

Fonte: https://sites.google.com/site/teoriasemetodologiashistoria

A reunião de diferentes tecnologias de informação e comunicação (TIC's) tem propiciado um viver cotidiano permeado por relações sociais digitais, quer no uso de celulares, tablets e notebooks (Whats App, Facebook, Twitter, Instagram, etc.), quer na própria acessibilidade educacional (comunidades virtuais, matrículas online, EaD, etc.). Experiencia-se o domínio do ciberespaço,

[...] um espaço social constituído simultaneamente pelas redes sociais que estabelecem culturas locais em seu interior e pelas redes técnicas que possibilitam essas conexões, é um lócus conveniente para a reflexão sobre a relação entre cultura e tecnologia. (GUIMARÃES JR., 2010, p. 49).

O historiador Marcos Silva (2011, p.18) ao compor um quadro sinóptico onde explica o "cenário sóciotécnico da cibercultura”, chama atenção para o aspécto social onde há um novo espectador mais interativo que migra da tela de TV e do joystick dos games para o mouse do computador conectado à internet, agregando várias funcionalidades e evitando argumentos lineares impermeáveis à sua participação ativa, alimentando sua experiência comunicacional. Do lado tecnológico, a internet permite ao internauta-interator a criação e o controle da informação, permitindo autoria e colaboração num ambiente de compartilhamento. 


\section{RESULTADOS}

A website "Teorias e Metodologias da História UFS" (https://sites.google.com/site/teoriasemetodologiashistoria/) propicia ao aluno um ambiente computacional para estudo, pesquisa e debate de textos dos autores Ronaldo Vainfas (2009), tratando da História Cultural, Jaques Revel (2010) sobre Micro-História, Brendan McSweeney (2009), refletindo as incoerências da cultura, Sandra Pelegrini (2008), abordando a gestão do patrimônio cultural, Luís Raposo (2003), analisando a musealização de sítios arqueológicos, dentre outros.

Assim, História e Museologia dialogam em suas convergências e especificidades, proporcionando aos alunos uma vivência interdisciplinar de conhecimentos necessários à sua formação, trazendo para o graduando um novo olhar para um objeto museológico e em tudo que o insere (campo museal).

0 acesso ao Google Analytics permite monitorar a visitação na website, identificando ainda a localização geográfica, o sistema operacional, o navegador e a forma pela qual o usuário chegou à página eletrônica. De posse dessas informações verifica-se a quantidade de vezes, o horário e tempo de permanência de alunos que acessam o site, permitindo aprimorar suas interfaces e avaliar o impacto da difusão dessa ferramenta de comunicação e ensino.

Imagens 4 e 5 - Dados referenciais de visitação de web por usuários

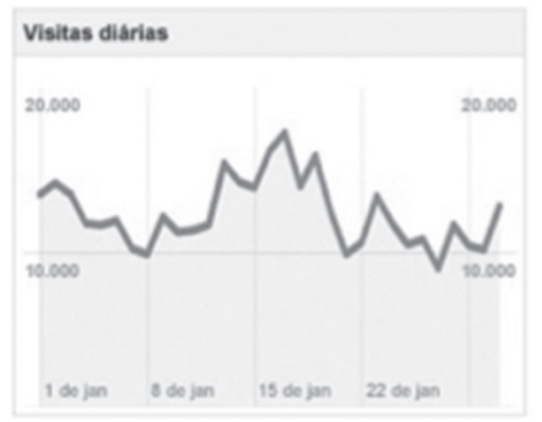

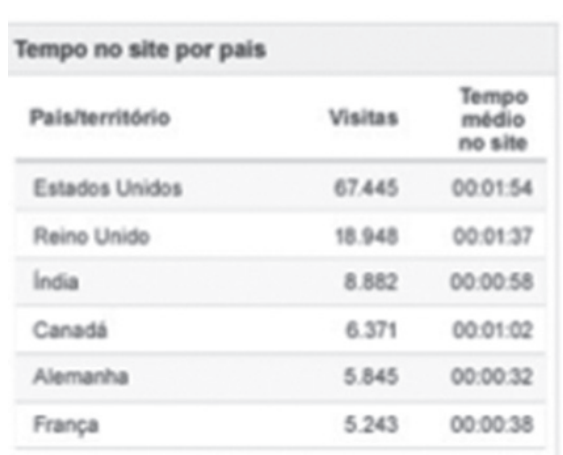

Fonte: Google Analytics

Por meio do uso das ferramentas estatísticas disponibilizadas pelo Google Analytics, foi possível identificar o quantitativo de acessos dos usuários da website que o faziam duas vezes por dia, todos os dias da semana.

Verificou-se, portanto, que a vinculação da website “Teorias e Metodologias da História UFS" à disciplina ministrada tornou o aprendizado mais prazeroso, desafiador e abrangente, resultando num índice de acessos por mais $80 \%$ dos alunos, com a aprovação de mais de $80 \%$ nas avaliações daqueles que fazem uso do site.

\section{DISCUSSÃO}

A ferramenta tecnológica amplia o espaço da sala de aula para a virtualidade da cibercultura, expandindo os horizontes da produção acadêmica e dando ao aluno um novo ambiente de estudo que o possibilita ter suas próprias ideias, tirar suas conclusões a partir da interpretação do assunto dado em sala de aula.

A Museologia enquanto ciência, ainda, é um campo extremamente novo no Brasil, tendo seus primeiros livros específicos no país publicados, na década de 1940, no Museu Histórico Nacional - no Rio de Janeiro - por Gustavo Barroso, seu primeiro diretor. A maioria de suas produções, ainda, possui um caráter muito técnico, entretanto, autores como Maria Cristina Bruno, Marília Xavier Cury, Mário Chagas, Maria 
Célia de Moura Santos trouxeram imensas contribuições para a elaboração e resignificação de conceitos e metodologias específicos e advindos de outras áreas.

Destarte, um site de Teorias e Metodologias da História para graduandos em Museologia intenciona fazê-los refletir sobre sua própria participação na construção e adequação conceitual e metodológica para objetos museológicos que sejam eleitos em suas pesquisas monográficas.

Partindo-se do pressuposto de que há uma multiplicidade de perfis em cada aluno que adentra a universidade a cada semestre, verificamos na graduação em Museologia da UFS desde usuários com muita afinidade tecnológica que dispõem de equipamentos pessoais móveis utilizando-os na instituição e em suas residências até aqueles que não possuem computador e sequer qualquer conhecimento de informática básica.

A criação de um site para uma disciplina ofertada no primeiro período permite identificar com precisão as potencialidades e defasagens em cada aluno, buscando sanar as ausências de conhecimento tecnológico por meio da oferta de oficinas de extensão em conhecimentos básicos em tecnologia e monitoria após as aulas.

O site ainda libera aos alunos mais tímidos uma interação maior no debate por meio de comentários; seduz os alunos das novas gerações que já fazem uso de tablets, celulares, aplicativos; desenvolve nos alunos o senso de autonomia com links que ultrapassam as indicações formais bibliográficas. Assim, "é no fluxo das trocas, idéias, conversas e debates que surgem as construções coletivas de conhecimento" (BARROS; MIRANDA, 2010, p. 61).

\section{CONCLUSÃO}

O site Teoria e Metodologias da História da UFS é uma ferramenta de auxílio, estímulo e desenvolvimento da aprendizagem dos graduandos em Museologia. $\mathrm{Na}$ área das Ciências Humanas e Sociais Aplicadas configura-se como uma inovação tecnológica, tendo em vista a disseminação recente desse ambiente computacional nesses campos do saber, aonde a difusão do conhecimento chega a um estado de difusão maior, possibilitando assim um novo estágio de aprendizagem.

Ao transpor o conhecimento teórico e metodológico em História do papel e da oralidade para o universo digital descortinam-se inúmeras possibilidades que ultrapassam barreiras geográficas e institucionais, despertando cada vez mais nos alunos/usuários a necessidade de visualizar e acompanhar as transformações decorrentes dessa nova era tecnológica. Desburocratiza-se a pesquisa e o ensino, conferindo ao aluno o papel de agente ativo em sua formação profissional.

\section{REFERÊNCIAS}

ABREU, Karen Cristina Kraemer. História e usos da Internet. Disponível em: <http://www.bocc.ubi.pt/ pag/abreu-karen-historia-e-usos-da-internet.pdf>. Acesso em: 10 out. 2013.

BARROS, Larissa; MIRANDA, Isabel. O papel das redes sociais para a construção e o compartilhamento do conhecimento em Tecnologias Sociais. In: Rede de Tecnologia Social - RTS (Brasil) (Org.) Tecnologia Social e Desenvolvimento Sustentável. Contribuições da RTS para a formulação de uma política de Estado de Ciência, Tecnologia e Inovação. Brasília-DF: Secretaria Executiva da Rede de Tecnologia Social (RTS), 2010. p.59-63.

\section{FAZENDA, Ivani C. A. Práticas interdisciplinares na} escola. São Paulo: Cortez, 1993.

FIGUEIREDO, Luciano. História e Informática: o uso do computador. In: CARDOSO, Ciro Flamarion; VAINFAS, Ronaldo (Orgs.). Domínios da História: ensaios de teoria e metodologia. Rio de Janeiro: Campus, 1997. 
GUIMARÃES JR., Mário José Lopes. Sociabilidade e tecnologia no ciberespaço. In: RIFIOTIS, Theophilos et al. (Orgs.) Antropologia no ciberespaço. Florianópolis: EDUFSC, 2010.

HEEMANN, Vivian. Avaliação ergonômica de interfaces de bases de dDados por meio de checklists especializados. 1997. Dissertação (Mestrado) - Florianópolis: Universidade Federal de Santa Catarina, Laboratório de Utilizibilidade (LablUtil), 1997.

HERNANDÉS, F. Manual de Museología. Madrid: Síntesis, 2001.

LEI no 7.287, de 18 de dezembro de 1984. Disponível em: <http://www.planalto.gov.br/ccivil_03/Leis/ L7287.htm>. Acesso em: 8 ago. 2014.

LÉVY, Pierre. Cibercultura. Trad. Carlos Irineu da Costa. São Paulo: 34, 1999.

MAYNARD, Dilton C.S. “Memórias do segundo dilúvio: uma introdução à história da internet”. In: MAYNARD, Dilton C.S Escritos sobre história e internet. Rio de Janeiro: Multifoco, 2011. p.15-42.

MCSWEENEY, Brendan. Incoherent culture. European J. Cross-Cultural Competence and Management, v.1, n.1, 2009. p.22-27.

MENESES, Ulpiano T. Bezerra de. Do teatro da memória ao laboratório da História: a exposição museológica e o conhecimento histórico. Anais do Museu Paulista. Nova Série, v.2, jan./dez. 1994. p.9-42.
PELEGRINI, Sandra. A gestão do patrimônio imaterial brasileiro na contemporaneidade. História, São Paulo, 27 (2): 2008. p.145-173.

RAPOSO, Luís. Benefícios e custos da musealização arqueológica in situ. Arqueologia e História, v.55, Lisboa: AAP, 2003. p.159-165.

REVEL, Jacques. Micro-história, macro-história: o que as variações de escala ajudam a pensar em um mundo globalizado. Revista Brasileira de Educação, v.15 n.45, set./dez. 2010. p.434-590.

SANTOS, Edméa. Cibercultura: o que muda na Educação. In: Cibercultura: o que muda na educação. Salto para o futuro/TV Escola. Ano XXI Boletim 3, abril, 2011. p.5-8.

SILVA, Marcos. A pesquisa e a cibercultura como fundamentos para a docência online. In: Cibercultura: 0 que muda na educação. Salto para o futuro/TV Escola. Ano XXI Boletim 3, abril, 2011. p.16-23.

SITE TEORIAS E METODOLOGIAS DA HISTÓRIA. Disponível em: <https://sites.google.com/site/teoriasemetodologiashistoria>. Acesso em: 10 out. 2013.

VAINFAS, Ronaldo. História Cultural e historiografia brasileira. História: Questões \& Debates, Curitiba, n.50, jan./jun. 2009. p.217-235. 
1. Pós-Doutoranda em Estudos Culturais (PACC-UFRJ); Doutoranda em Propriedade Intelectual (PPGPI-UFS); Doutora em História Social (PPGHIS-UFRJ); Professora Adjunta da Graduação em Museologia (UFS) e dos Mestrados em Avaliado em: 30 de dezembro de 2014 Aceito em: 20 de abril de 2015

História (PROHIS-UFS e PPGH-UFAL); Líder do Grupo de Estudos e Pesquisa em Memória e Patrimônio Sergipano (GEMPS/CNPq).

E-mail: janainamello.ufs@gmail.com

2. Graduando em Museologia pela UFS. Monitor da disciplina de Teorias e Metodologias da História (PROGRAD). E-mail: jheansouza97@gmail.com 